\title{
Sobre ser professor-artista-etc e vice-versa, ou como construir escolas de arte
}

\author{
Mônica Hoff Gonçalves
}

\begin{abstract}
Resumo
Entre 1970 e 1974, Allan Kaprow escreveu aqueles que seriam textos seminais para pensar as relações entre arte, filosofia e educação no contexto da arte. Refiro-me aqui à trilogia A educação do an-artista. As partes I e II do texto, publicadas no Brasil nos anos de 1990, têm sido constantemente analisadas, discutidas e atualizadas em debates internacionais sobre as contribuições do artista para os campos da arte e da educação (da arte) há, pelo menos, duas décadas. Sobre a parte III, no entanto, ainda se versa muito pouco. O presente artigo busca, a partir de ponderações feitas por kaprow nesta última parte da trilogia, e, principalmente, do que ali não está contemplado, refletir e discutir sobre projetos que pensam artisticamente a academia, ou projetos de arte que se apresentam como escolas, e o papel do artista-professor.
\end{abstract}

\section{Abstract}

Between 1970 and 1974, Allan Kaprow wrote those seminal texts that would be very important to think about the relationship between art, philosophy and education in the context of art. I refer here to the trilogy The education of an-artist. Parts I and II of the text, published in Brazil in the 1990s, has been constantly analyzed, discussed and updated in international discussions about the contribution of the artist to the fields of art and education since the mid-1990s. About part III, however, there are very few discussions and reflections. This article seeks, from considerations made by kaprow in this last part of the trilogy, and especially from what the text does not speak, reflect and debate about projects that think the academia from an artisticaly perspective, or art projects that arise as schools, and the role of the artist-teacher.

Em A educação do an-artista III $^{2}$ (1974), última parte da trilogia que Allan Kaprow jogou para o mundo na primeira metade da

\footnotetext{
1 Este artigo foi concebido a partir das leituras e discussões geradas no contexto da disciplina Sobre ser professor-artista, ministrada pela Profa. Dra. Jociele Lampert junto ao Programa de Pós-graduação em Artes Visuais da UDESC, no segundo semestre de 2015.

2 Na primeira metade da década de 1970, o artista norte-americano Allan Kaprow escreveu A educação do an-artista, publicada em três partes, sendo a primeira em 1971; a segunda em 1973; e a última em 1974. As duas primeiras foram traduzidas para o português e a terceira pode ser acessada apenas em versões em inglês e espanhol. Para acessar a Parte I, ver KAPROW, Allan. A educação do an-artista I. In: Concinnitas / IA/UERJ, Rio de Janeiro, v. 4, n. 4, 2003. Disponível em https://cidadaniaearte.wordpress.com/2014/11/13/a-educacaodo-an-artista-parte-1/.Para a Parte II, ver A educação do an-artista II. In: Concinnitas / IA/UERJ, Rio de Janeiro, ano 5, n. 6, 2004. Disponível em http://issuu.com/websicons4u/docs/revista6/169. (Parte II). Para acessar a Parte III, ver (em inglês) KAPROW, Allan. Essays on the blurring of art and life. Org. Jeff Kelley. Berkeley, Los Angeles, London: University of California Press. 1993; e (em espanhol) KAPROW, Allan. La educación del des-artista. Madrid: Ediciones Ardora, 2007.
}

$$
=28=
$$

ISSN: 2447-1267 Santa Catarina, v.5, n.1, ano 3, março de 2017. 
década de 1970, o artista argumenta que os modelos de arte experimental daqueles tempos, e sobretudo daquela geração, não eram tanto as pautas herdadas ou procedentes do campo da arte mas as formas sociais engendradas no período, particularmente como e o quê se estava comunicando, como o processo afetava o trabalho e as investigações, e como isso levava a conexões com processos naturais para além do campo social.

Kaprow acreditava que, até então, embora os artistas estivessem conscientes, em alguma medida, da "natureza do universo físico, das ideias e de assuntos humanos ${ }^{\prime 3}$ suas proposições ainda eram traduções de tais processos e vivências, portanto, obras de arte ${ }^{4}$. De acordo com sua leitura ("daquele mundo naquele momento"), a vida era compreendida em si como "um modelo secundário; um artista frequentava a escola de arte para estudar arte, não a vida" ${ }^{5}$. Esta lógica, segundo Kaprow, estaria, contudo, mudando ele acreditava que estava-se vivendo, naqueles anos, uma espécie de turning point no contexto, principalmente, das práticas artísticas.

Para dar visibilidade a tal giro, na parte III de sua educação do an-artista, Kaprow se propôs um exercício bastante simples: tratou de elencar a partir de cinco modelos ${ }^{6}$ (categorias) que, segundo ele, poderiam ser encontrados tanto na vida cotidiana como nas profissões não-artísticas ou na natureza, uma série de exemplos do que acreditava ser uma nova métrica em termos de produção e pensamento artísticos.

Dentre tais modelos, um nos chama especialmente a atenção, trata-se do modelo de aprendizagem, o qual o artista divide em três eixos (ou formatos distintos): alegorias de questões/investigações filosóficas; rituais de sensibilização; e manifestações educativas. No primeiro refere-se, principalmente,

\footnotetext{
3 Ver KAPROW, Allan. Essays on the blurring of art and life. Org. Jeff Kelley. Berkeley, Los Angeles, London: University of California Press. 1993. p. 140. tradução nossa.

${ }^{4}$ Equação esta que o próprio Kaprow buscou desconstruir com intensa reflexão na parte I da trilogia. Refiro-me aqui às divisões arte-Arte, não-arte e an-arte propostas pelo artista na parte I de A educação do an-artista. Ver KAPROW, Allan. A educação do an-artista I. In: Concinnitas / IA/UERJ, Rio de Janeiro, v. 4, n. 4, 2003. Disponível em http://www.concinnitas.uerj.br/arquivo/revista4.htm Acesso em 19/03/2012
}

\footnotetext{
${ }^{5}$ Ver KAPROW, Allan. Essays on the blurring of art and life. Org. Jeff Kelley. Berkeley, Los Angeles, London: University of California Press. 1993.p. 139-140. tradução nossa.

São eles: modelos de situação, operacionais, estruturais, auto-referenciais e de aprendizagem.
}

$$
=29=
$$


a processos e pensamentos filosóficos e educativos transformados em formas e dispositivos de arte. O segundo, por sua vez, vincula-se a uma ideia de experiência coletiva de sensibilização em que a noção de espectador se deixa nublar diante da possibilidade de participação ativa das pessoas, uma vez que é isso o que confere sentido ao próprio ritual/experiência. O terceiro, por fim, poderia compreender tanto os programas e cursos propostos por artistas em contextos e situações artísticas (dentro de galerias e museus, em espaços expositivos, e bienais e feiras de arte, se levarmos em conta o contexto atual), como as metodologias artísticas propostas por artistas em outros ambientes, situações e contextos que não os, até então, designados para a exibição de arte (como uma sala de aula, por exemplo). Neste caso o que se torna turvo não são as noções de artista e espectador, mas do que é arte e do que é pedagogia.

Os elementos (e exemplos) apresentados por Kaprow, relatados nesta breve introdução, poderiam constituir sem dúvida e desde já um corpo de investigação bastante interessante para o presente ensaio. No entanto, fugiremos disto. Gostaríamos de abordar aqui algo que, embora pareça tangenciar os três eixos do modelo de aprendizagem e integrar o pensamento de Kaprow, não é tratado, tampouco mencionado, ao longo da terceira parte de A educação do an-artista. Talvez, sequer percebido pelo artista naquele momento.

Desta forma, tal qual propõe Walter Benjamin em uma de suas teses sobre o conceito de história ${ }^{7}$, versaremos sobre aquilo que no passado não parecia estar presente mas que numa leitura feita nos dias de hoje parece reclamar seu lugar, nos levando, portanto, a uma reinvenção do passado, alterando por conseguinte nosso presente.

Referimo-nos à noção de escola de arte ${ }^{8}$ como site specific. ou seja, a escola de arte como um lugar pensado artística e criticamente a partir de suas especificidades materiais,

Referimo-nos aqui, principalmente, às teses 6 e 7 nas quais Benjamin declara a necessidade de desviarmos da história como processo de transmissão cultural dominante. Segundo o autor, é preciso "escovar a história a contrapelo", vê-la e esmiucá-la ao revés. Ver BENJAMIN, Walter. Obras escolhidas. Vol. 1. Magia e técnica, arte e política. Ensaios sobre literatura e história da cultura. Prefácio de Jeanne Marie Gagnebin. São Paulo: Brasiliense, 1987, p.222-232.

${ }^{8}$ Incluimos nesta compreensão universidades e academias de arte. O sentido de escola de arte exposto aqui é o das instituições de formação em e sobre arte, formais e não-formais, que se compreendem como tal.

$$
=30=
$$

ISSN: 2447-1267 Santa Catarina, v.5, n.1, ano 3, março de 2017. 
conceituais, operacionais, físicas, humanas, econômicas, políticas e sociais e que, além de saberes experimentais do ponto de vista pedagógico, produz também metodologias, "modos de vida" e de organização específicos, os quais geram novas possibilidades de pensar o campo da arte, a prática artística, bem como os papéis do artista e do professor.

Esta temática é verificada, em algum grau, por Ricardo Basbaum no texto O artista como pesquisador, quando este debate sobre a atuação do artista e o lugar da pesquisa em arte na universidade, e o fato de a universidade fazer parte de um circuito mais amplo, pertencente ao sistema da arte. Embora pensar a universidade como campo específico para a prática artística não seja - foco central do texto - Basbaum está centrado em debater as relações conflitantes, porém, proveitosas e produtivas entre este universo e o circuito da arte - o artista sugere atentarmos aos novos territórios que esta "dobra" a mais no sistema da arte - no caso, a universidade - pode oferecer. Basbaum nos pergunta: "que caminhos podem ser inaugurados? Quais possibilidades podem ser apontadas? Se tomarmos a arte enquanto produção de conhecimento e processamento sensorial, quais modos problematizadores são trazidos para o primeiro plano?"."

Principalmente no decorrer das décadas de 1960-70, mas também no decurso de todo o século Xx, muitos artistas estiveram diretamente envolvidos com a criação e gestão de escolas de arte, com a preparação de currículos, cursos, disciplinas e programas de aula, pensando prática artística e prática de ensino como aspectos de uma mesma atividade. Em linhas gerais, poderíamos dizer que as escolas de arte surgiram, originalmente, por demanda dos artistas, logo, seriam eles seus principais pensadores. Isto se vê com maior força, seguramente, a partir das vanguardas artísticas do começo do século XX, com o advento da noção de arte como campo de conhecimento autônomo. Logo, como um "lugar" com normativas e métodos próprios, e com seu próprio sistema. Mas pode ser observado antes também, se considerarmos que as escolas de arte decorrem, principalmente, das práticas em/de atelier, às quais remontam o século XV.

\footnotetext{
9 Ver BASBAUM, Ricardo. O artista como pesquisador. In: BASBAUM, Ricardo. Manual do artista-etc. Rio de Janeiro: Beco do Azougue, 2013.p. 195.
} 
Apesar disso, reflexões acerca das especificidades deste "lugar" como determinantes para um pensamento em arte (prática artística + debate críticol ainda seguem raras. No geral, a universidade é (compreendida como) o lugar onde se pesquisa, não o campo $^{10}$ da pesquisa ou da experiência em si. Ou seja, um lugar que investiga o mundo da arte (suas teorias, pedagogias e práticas), mas não se inclui nele. Parece contraditório, considerando que as escolas de arte têm sua origem, como acabamos de mencionar, principalmente na prática artística e no desejo de artistas de compartilhar e pensar mais sobre seus métodos; além de sintomático, se levarmos em conta a relação historicamente conturbada entre arte e educação que se convencionou criar no contexto da arte.

Tal paradoxo fica ainda mais evidente quando nos damos conta que alguns dos grandes exemplos de prática artística, especialmente no século Xx, que perduram e são constantemente revisados, citados e atualizados, são justamente as escolas de arte experimentais e as iniciativas de artistas no campo da educação. Talvez o uso de alguns exemplos possa nos ajudar a ver isso melhor.

No que tange à primeira metade do século XX, poderíamos destacar as experiências levadas a cabo, principalmente, pelos construtivistas russos, ressaltando as investigações exemplares de Malevich e seu envolvimento com o UNOVIS ${ }^{11}$, quando professor da Vitebsk Art School; por Walter Gropius, na Alemanha, com a fundação da primeira Bauhaus ${ }^{12}$ (1919-23); além da participação ativa e ativista de Josef Albers, dissidente da Bauhaus, na construção em tempo real do Black Mountain College (1933-57), chegando a ser reconhecido como força central da escola.

\footnotetext{
${ }^{10}$ No sentido usado pela antropologia, de fazer campo.

${ }^{11}$ Grupo de artistas formado por Malevich e seus alunos, em 1919, na Vitebsk Art School (1897-1923), Russia. O significado de UNOVIS é "Utverditeli Novo Iskusstva" ou algo como "Os Campeões da Nova Arte".

${ }^{12}$ Como primeira Bauhaus entendemos a primeira fase da escola, que poderia, de acordo com sua história, ser dividida em 3: Bauhaus-Weimar (1919-23), em que o ensino era o fundamento principal, constituindo-se como uma escola livre no sentido de não seguir dogmas; Bauhaus-Dessau (1923-1928), já mais focada numa aproximação direta com a indústria e a produção em série, estruturando-se como uma própria indústria de conhecimento; e Bauhaus-Berlim (1929-1933), talvez ainda mais dogmática que a segunda quanto à sua função na formação de designers e arquitetos e, por isso, cada vez mais contrária às premissas que a originaram, o que acabou gerando sua dissolução .
}

$$
=32=
$$


Embora não compartilhem o mesmo contexto político, social e cultural - afinal, estamos falando da Rússia da virada do século diante do processo de industrialização; da Alemanha pós-Primeira Guerra frente à retomada do país; e dos EUA da Grande Depressão; tampouco o mesmo tempo histórico - praticamente uma é inaugurada quando a outra encerra suas atividades -, as três escolas dividem uma ideia comum de universalidade da arte, mesmo que, na prática, para isso, tracem caminhos distintos. Vitebsk ${ }^{13}$ faz a partir da teoria suprematista de Malevich; a Bauhaus, originalmente como um projeto de um homem só - Gropius - e sua proposta de, ao mesclar arte, artesanato e indústria, formar profissionais mais universais; e o Black Mountain College, coordenada por um artista, através de sua organização como uma espécie de liberal arts school ${ }^{14}$, aberta a artistas e não-artistas, que defendia a prática ante a teoria, o 'aprender fazendo' e a investigação mais do que a produção de arte e que não pretendia formar ninguém em coisa alguma, convertendo-se, por conta disso, numa das mais importantes experiências de educação (da arte) do século Xx.

O que podemos perceber com estas experiências é que mais do que pedagogias instituintes que se converteram em escolas de arte, tratou-se, sobretudo, de investigações no campo da prática artística que levaram a teorias (da percepção) que acabaram, então, gerando novas pedagogias e estas, modelos mais experimentais de escolas. De certa forma, foi a soma destas experiências que, por contraste e complementaridade, fabricaram a noção de escola de arte

\footnotetext{
${ }^{13}$ Vitebsk se transformou, de certa forma, na escola de Malevich. O artista desenvolveu sua teoria suprematista durante os anos em que esteve em Vitebsk, a partir de sua prática como professor. O ensaio teórico "Dos novos sistemas na arte", em que o artista busca estabelecer os princípios de uma pintura abstrata vinculada às experiências contemporâneas, foi impresso em 1919, em um workshop de litografia realizado com estudantes na escola de arte. Atualmente, seria possível afirmar que muito do que conhecemos da Vitebsk School of Art advém das iniciativas e experiências propostas por Malevich nos anos em que lá esteve. Ele tentou introduzir um novo tipo de ensino da arte, no qual todas as formas de arte eram desenvolvidas tendo como base o Suprematismo, sendo integradas dentro de um sistema universal.
}

O termo liberal arts surgiu na Grécia antiga como uma espécie de formação multidisciplinar com o objetivo de preparar o homem, em sua prática individual, para a vida em sociedade de modo que pudesse se posicionar e defender publicamente, servir ao governo, etc. Atualmente, consiste numa formação universitária de caráter amplamente interdisciplinar com currículo formado por áreas e disciplinas que, no geral, envolvem ciências sociais, ciências naturais, humanas (letras, artes, etc) e exatas (matemática, lógica, estatística) e também com o objetivo de possibilitar uma formação mais "global" ao cidadão. Este tipo de formação se popularizou nos EUA na segunda metade do século XX e, mais recentemente, na Europa, e é compreendida como uma formação completa que visa auxiliar o homem nos mais diversos campos do conhecimento e áreas de atuação profissional.

$$
=33=
$$


que vigorou ativamente ao longo do século XX. Como escolas fundadas e/ou geridas por artistas, elas acabaram assumindo ideias individuais, que foram reelaboradas num plano coletivo.

No que diz respeito à segunda metade do século XX, principalmente aos anos de 1960-70, há uma renovação por parte dos artistas com relação à educação, conferindo novos contornos à noção de escola de arte. De fato, há uma intensa participação de artistas junto a escolas de arte e universidades, mas desta vez, de uma maneira menos afirmativa e mais desconstrutiva da instituição e seus valores - talvez pudéssemos encontrar aí indícios do que alguns anos depois viríamos chamar de crítica institucional - que leva muitos deles à concepção de escolas autônomas, universidades livres e academias independentes nas quais, no geral, as distinções entre prática artística e prática de ensino se diluem através da mediação do cotidiano, do ordinário, da prática da vida diária.

Exemplos pertinentes desta nova configuração seriam as aulas-atividades de Kaprow no CalArts, principalmente, nos anos de 1960-70; o envolvimento político de Joseph Beuys ${ }^{15}$ como professor da Academia de Artes de Dusseldorf, fundando com seus estudantes o Partido dos Estudantes e abrindo suas aulas para mais de 400 pessoas, dentre as quais estavam alunos e não-alunos da escola, e a posterior criação da Universidade Livre Internacional ${ }^{16}$; a criação da Lidl School, por Jorg Immendorf, dentro da Academia de Artes de Dusseldorf, quando aluno de Beuys; as oficinas Pluridimensionais oferecidas por Helio Eichbauer no Parque Lage, que se converteram em performances-aulas conformando boa parte da aura de experimentalismo atribuída à escola até hoje; a própria criação do Parque Lage (1975), que teve como idealizador e primeiro diretor o artista Rubens Gershman; a criação da Non-École de Villefranche, por Robert Filliou e Georg Brecht no litoral francês no fim da década de 1960, que consistiu numa loja-escola-ateliê; o projeto do New Marlborough Centre for Arts, proposto por George Maciunas, que pretendia ser um misto de Bauhaus e Black Mountain College, e que

\footnotetext{
5 Para compreender mais profundamente a atuação e posicionamento de Joseph Beuys como professor e as consequências políticas sofridas por ele, principalmente, no contexto da Escola de Artes de Dusseldorf, ver SARMiento, José Antonio. La clase de Beuys. Cuenca: Une, 2015.

${ }^{16}$ A Free International University (FIU) foi fundada por Joseph Beuys e Heinrich Böll em

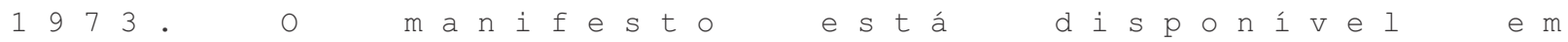
<https://sites.google.com/site/socialsculptureusa/freeinternationaluniversitymanifest o) Acesso em 05/02/2016
}

$$
=34=
$$

ISSN: 2447-1267 Santa Catarina, v.5, n.1, ano 3, março de 2017. 
ocorreria em Massachusets caso tivesse se concretizado; ou mesmo, a série de pinturas tituladas Art Lesson, de John Baldessari, bem como sua experiência como professor no Cal-Arts; a experiência do Artist Placement Group, iniciativa concebida originalmente por Barbara Steveni em 1965, e fundada um ano mais tarde por Barbara, Barry Flanagan, David Hall, John Latham, Anna Ridley and Jeffrey Shaw em Londres; a Eksperiment Kunst Skolen (1961-69) fundada por um grupo de artistas dinamarqueses; e no Brasil, a experiência da Escola Brasil (1968), em São Paulo, levada a cabo pelos artistas José Resende, Carlos Fajardo, Luis Paulo Bravelli e Frederico Nasser; e da ASTER (1978-81), escola de arte experimental criada por Regina Silveira, Julio Plaza, Walter Zanini e Donato Ferrari; para citar alguns exemplos.

Atualmente, ou seja, com certo distanciamento histórico, e considerando as produções e debates ao redor da virada educacional nas práticas artísticas contemporâneas, realizados sobretudo nas últimas duas décadas (que verificaram um boom de escolas fundadas por artistas em contextos domésticos, barcos, caminhonetes, praças, bicicletas, dentro de exposições, em bienais de arte, como programas temporários e, inclusive, dentro das próprias escolas de arte ${ }^{17}$ ), poderíamos considerar ou mesmo nominar

Dentre elas podemos citar Mildred's Lane Project (Mark Dion, 1998) / Cittadellarte / École Temporaire (Dominique Gonzalez-Foerster, Philippe Parreno e Pierre Huyghe, 1998-1999) / Proto Academy (Charles Esche, 1998-2002) / The Independent Art School (1999) / School for the History and Theory of Images (Branimir Stojanovic, 1999) / The Real Presence (Biljana Tomic, desde 2000) / Copenhagen Free University (Henriette Heise e Jakob Jakobsen, 2001-07) / ArtSchool Palestine (2001) / Campus 2002 (Marius Babias e Florian Waldvogel) / Gasthof 2002 at Staedelschule, Frankfurt / School of Missing Studies (2002-) / Future Academy (Clementine Deliss, 2002) / University of Openness (2002) / Cátedra Arte de Conducta (Tania Bruguera, Havana, 2002-09) / Escuela Panamericana del Desasosiego (Pablo Helguera, 2003-06) / Manoa Free University (2003-2008) / Informal University in Foundation (2003) / The Paraeducation Department (Sarah Pierce e Annie Fletcher, 2004) / Cork Caucus (2004-05) / Momentary Academy (Ted Purves, 2005) / Mountain School of Art (Piero Golia e Erik Wesley, 2005) / ArtSchool Palestine (2005) / Escuela Móvil de Saberes y Practica Social (2005) / Manifesta 6 School (2006) / Escuela de Arte Belleza y Felicidad de Villa Fiorito (2006) / Brown Mountain College (2006) / Unitednationsplaza (2007) / Potential School (Liam Gillick, 2007) / Islington Mill Art School (2007) / The Public School (2007) / The Independent Art School (2009) / Night School (2009) / Parallel School (2009) / Picketpocket Almanck (Joseph del Pesco, Franck Leibovici, Sébastien Pluot, Vivian Rehberg, Eric Périer e Mathieu Kleyebe Abonnenc, 2009) / Department 21 (2009) / Institut für Raumexperimente (Olafur Eliasson, 2009) / MASS Alexandria (2010) / Trade School (2010) / Campus (Libia Castro \& Ólafur Ólafsson, Renata Lucas, Peter Piller e Adrià Julià, 2011) / Turps Art School (Marcus Harvey e Peter Ashton, 2012) / Göteborgs Autonoma Skola / Workers Punk Art School (Hito Steyerl, 2008-09) / Center for Land Use Interpretation (Damon Rich) / Machine Project / The Anhoek School / Mobile Academy / Centre for Possible Studies (Janna Graham e Sally Talant) / La Ivan Illich (Beta-Local, San Juan, Puerto Rico) / Open School East (2013) / Fairfield International Art School (Ryan Gander, 2015) / Escuela de Garaje (Laagencia, Bogotá, 2015) / Amen Foundation (Abdulnasser Gharem, 2015) / Surf school-etc (Mônica Hoff, 2015) / The Antiuniversity Research Project (Jakob Jakobsen, London, 2015), entre outras. Ver GONÇALVES, Mônica. Universidades livres, DIY schools, academias caseiras: as escolas de artista contemporâneas. In: GONÇALVES, Mônica. A virada educacional nas práticas artísticas e curatoriais contemporâneas e o contexto de arte brasileiro. Dissertação de mestrado. Porto Alegre: PPGAV/UFRGS, 2013. pp. 121-142

$$
=35=
$$


tais experiências - compreendidas originalmente como aulas, planos de aula, cursos, palestras, disciplinas, currículos, e as próprias escolas - como projetos artísticos. Ou, no caso específico das escolas, de escolas de artistas, uma vez que a o desenvolvimento e a autoria das metodologias (artísticas) empreendidas é o que confere forma a estes espaços.

No entanto, esta equação não é tão simples quanto aparenta - e sua complexidade está menos relacionada ao fato de que não seria fácil categorizar tais experiências e mais ao feito de que, ao categorizá-las, tendemos a legitimá-las como "coisas artísticas" que passam a ser analisadas na academia como "objetos de arte" externos a ela - ou seja, como traduções, ou obras de arte, tal qual citara anteriormente Kaprow.

Numa matemática simples seria algo como importar o que se exporta - o que pode ser interpretado como um movimento interessante do ponto de vista conceitual, uma vez que, ao importar - que antes se havia exportado, sendo este algo o conhecimento, então, pelo menos em teoria, a academia garante que o conhecimento esteja em constante transformação. Por outra parte, contudo, ao fazê-lo, ela tende a olhar para este conhecimento - organizado no formato de aulas, currículos, planos, atividades, escolas - como um objeto de análise, valendo-se menos, portanto, de suas especificidades metodológicas, desconstrutivas e transformadoras do ponto de vista pedagógico, e mais dos seus efeitos artísticos.

Diante disso, nos perguntamos: como analisar tais iniciativas? Elas devem ser avaliadas? Sob que perspectiva? Desde que lente? No que diz respeito aos artistas, por que eleger a academia, escola de arte ou universidade como território no qual ou a partir do qual realizar intervenções e práticas artísticas? ${ }^{18}$ Qual o sentido político desta escolha? Para, ou com, quem se quer falar? No que tange à escola de arte, como ela e seus atores lidam com um conhecimento que nasce como uma metodologia artística, criada especificamente para seu contexto, muitas vezes decorrente de uma investigação feita nos campos da filosofia e da educação ${ }^{19}$, que se

\footnotetext{
${ }^{18}$ Esta pergunta inaugura o texto "Mantener las Formas: la academia en y desde las prácticas artísticas", de Selina Blasco. In: BLASCO, Selina (Org.). Investigación artística y universidad: materiales para un debate. Madrid: Ediciones Assimétricas, 2013.

19 Os exemplos mais conhecidos são o próprio Allan kaprow e a influência sofrida pelas teorias de John Dewey; e Joseph Beuys, o qual tinha como seu principal mentor filosófico Rudolf Steiner.
} 
converte em objeto artístico? Ou, como ela lida com metodologias artísticas que se transformam em pedagogias que geram escolas de arte como projetos de arte? E, ainda, de que forma e em que medida as escolas caseiras, autônomas, livres e/ou independentes - escolas de artistas, como chamamos anteriormente - podem gerar processos de revisão nas escolas e academias de arte? Como a experiência das escolas de artistas pode gerar debates e transformações significativos nas escolas de arte, as quais não podemos nos esquecer têm seu germe nas escolas de artistas, ou seja, são originárias de metodologias criadas por artistas?

E, por fim, quando, e sob que circunstâncias, uma aula, um curso, uma palestra ou um plano de aula é considerado arte e quando, e sob que circunstâncias, é considerado pedagogia? o que exatamente tais definições ocasionam, e o que negligenciam ou esquecem de considerar?

Ao que parece, pensar a escola de arte como campo de pesquisa específico implica muito mais do que podemos supor. Não se trata, certamente, de uma matemática simples, tampouco exata. E, talvez, seja justamente o fato de ser uma orquestração inconciliável o que leva artistas a pensá-la como uma potente forma de arte. Mais do que mais uma categoria artística a ser analisada, as escolas de arte empreendidas por artistas, ou escolas de artistas, se efetivam como um problema filosófico para o campo, uma vez que o caráter autorreferente da arte, ou seja, de observar-se e pensar-se como campo e portanto poder colocar em cheque suas próprias normas, encontra o político como condição de existência, ou seja os acordos sociais, as normativas, regras, questões étnicas, de gênero, hierarquias e relações de poder das quais não podem escapar. Mas não é esta a condição de existência da arte? De nublar as definições, de reinventar constantemente suas próprias diretrizes, de ser o quiser ser, e, assim, ser coisa política?

Se optarmos por responder que sim, provavelmente compreenderemos que uma das grandes contribuições das escolas de artistas para o campo da arte é que elas muito apropriadamente "bagunçam" as fronteiras epistemológicas e zonas de poder existentes entre prática artística, ensino e teoria da arte, tornando impossível de serem definidas como isto ou aquilo. São ora estruturas fixas ora estruturas móveis; não assumem identidades permanentes; no geral, assumem o conceito de autoinstitucionalização; tem uma natureza aleatória e/ou aberta; uma $=37=$

ISSN: 2447-1267 Santa Catarina, v.5, n.1, ano 3, março de 2017. 
preferência por abordagens exploratórias, experimentais, e multidisciplinares em termos de produção de conhecimento; uma consciência em relação à instrumentalização da academia; uma tendência para o processo mais do que para o objeto; assumem-se como uma escola que funciona como um meio social que prioriza a produção colaborativa e que lida com uma temporalidade contínua e potencialmente infinita. Trata-se, no entendimento da crítica, acadêmica e artista Kristina Lee Podesva", de "um ambiente de aprendizagem pós-hierárquico, onde não existem professores, apenas co-participantes". Uma proposição que busca desviar da chamada "economia do conhecimento" que vem cimentando e constrangendo o sistema de ensino, principalmente, desde a virada do milênio. E para o qual as próprias escolas de arte, pelo menos em teoria, torcem o nariz. Os artistas estão respondendo a isso. Ao criarem escolas experimentais, eles estão fazendo um exercício de imaginação institucional. Um exercício que é concomitantemente poético, político e pedagógico. Um exercício necessário de reinvenção.

Diante disso, poderíamos nos questionar, como num último suspiro, para que servem, então, hoje, as escolas de arte? Se for para formar artistas que pensem e façam escolas de arte já podemos nos dar por felizes.

\footnotetext{
${ }^{20}$ Ver PODESVA, Kristina Lee. A Pedagogical Turn: Brief Notes on Education as Art. In: Filip 6, Vancouver, $\mathrm{n}^{\circ}$ 6, 2007. Disponível em: <http:/fillip.ca/content/a-pedagogical-turn>
} 
Mônica Hoff Gonçalves é doutoranda em Artes Visuais na linha de Processos Artísticos Contemporâneos, sob a orientação da Profa. Dra. Regina Melim Cunha, no PPGAV/UDESC. Mestre em Artes Visuais, na linha de História, Teoria e Crítica de Arte, pelo PPGAV/UFRGS (2014), com pesquisa financiada pela CAPES; especialista em Pedagogia da Arte, pelo PPGEDU/UFRGS (2008); e bacharel em Artes Plásticas pelo IA/UFRGS (2002). Atua como artista, curadora e pesquisadora, com pesquisa no âmbito das relações entre arte e educação no contexto artístico contemporâneo com especial atenção para temas como mediação cultural, públicos, curadoria educativa e programas públicos. De 2006 a 2014, foi responsável pela coordenação geral do Projeto Pedagógico da Bienal do Mercosul (POA/BR), atuando também como curadora de base na nona edição do evento, realizada em 2013. Desde então vem colaborando com instituições culturais como Colección Cisneros, Alumnos 47, Casa Daros, New Museum, Liverpool Biennial, Instituto Mesa, Circuito Líquido, entre outros. Em 2011 e 2013, respectivamente, organizou as publicações Pedagogia no campo expandido, com Pablo Helguera; e A Nuvem e Manual para Curiosos, com Sofía Hernandez Chong Cuy.

http://lattes.cnpq.br/2582745531405339 b 